\title{
Miao Chinese
}

National Cancer Institute

\section{Source}

National Cancer Institute. Miao Chinese. NCI Thesaurus. Code C158163.

A Chinese person from the Miao (Including Hmong) ethnic group. 